\title{
Evaluation of Mechanical Properties of a Superalloy Disk with a Dual Microstructure
}

\author{
Yu Tao ${ }^{1,}$, Jiantao Liu', Yiwen Zhang ${ }^{1}$ \\ ${ }^{1}$ Central Iron \& Steel Research Institute, No. 76 Xueyuan Nanlu, 100081 Beijing, PR China \\ atao-yu@vip.sina.com
}

\section{Key words: FGH96, P/M superalloy, dual microstructure, mechanical property}

\begin{abstract}
The main purpose of this paper is to evaluate the mechanical properties of a FGH96 alloy disk with a dual microstructure. FGH96 is a powder metallurgy (P/M) processed disk alloy, which was developed in the 1990s in China. The manufacturing processes used to produce the FGH96 disk with a dual grain structure consisted of atomization by plasma rotating electrode process (PREP), hot isostatic pressing (HIP), isothermal forge, special heat treatment for obtaining dual grain structure and final heat treatment. The disk was cut up and completely evaluated. Mechanical properties, including tensile, stress rupture, plastic creep, low cycle fatigue, fatigue crack growth rate, fracture toughness, impact and hardness, were tested at room and higher temperatures. In addition, a detailed grain characterization of the disk, from rim to bore, was also presented.
\end{abstract}

\section{Introduction}

In recent years a new technology has been developed to manufacture turbine disks with dual microstructure. This kind of disks can meet the design requirements for that a much higher tensile strength and a low cycle fatigue (LCF) life for large centrifugal stress in the bore region, while superior high temperature creep and fatigue crack-growth properties are necessary in the rim region to withstand high temperatures as well as high thermal and centrifugal stress. Some methods for producing dual-microstructure components have been described in literatures $[1,2,3,4]$. All of them have the same principle. The disk is first prepared usually by isothermal forging to have a uniform fine grain microstructure. Then during a special heat treatment a temperature gradient is established from rim to bore of the disk. The rim region is held above the $\gamma^{\prime}$ solvus temperature to remove $\gamma^{\prime}$ precipitates, that allows grain growth to provide a coarse grain microstructure. While the bore region remains below the $\gamma^{\prime}$ solvus temperature, the grain growth is restricted by $\gamma^{\prime}$ precipitates, and that retains the initial fine grain microstructure.

FGH96 is a powder metallurgy $(\mathrm{P} / \mathrm{M})$ processed nickel-base superalloy, which was developed in the 1990s in China and has been used for manufacturing the rotor components of aircraft engines. This alloy has a nominal composition in mass percent of $2.2 \mathrm{Al}-0.01 \mathrm{~B}-0.025 \mathrm{C}-0.01 \mathrm{Ce}-13 \mathrm{Co}-16 \mathrm{Cr}-4 \mathrm{Mo}-$ $0.8 \mathrm{Nb}-3.7 \mathrm{Ti}-4 \mathrm{~W}-0.038 \mathrm{Zr}-\mathrm{Bal}$. Ni [5]. The mass fraction of $\gamma^{\prime}$ in heat treated FGH96 alloy is about $34.6 \%$ [6]. In a previous paper the effects of grain size on mechanical properties of FGH96 alloy were studied [7]. It was found that specimens with fine grain size offer better tensile and fatigue properties while specimens with coarse grain size offer better stress-rupture and creep properties. On this base, a FGH96 disk was produced and treated to have a dual microstructure. This paper presented the characterization of the microstructure and mechanical properties in bore, web and rim regions of the disk.

\section{Materials and Procedure}

FGH96 disks were produced by a processing rout with hot isostatic pressing plus isothermal forge. In powder manufacture, vacuum induction melted rods were atomized by plasma rotating electrode process (PREP). The powder was canned in vacuum, hot isostatically pressed and then isothermally forged into a disk with dimensions of about $460 \mathrm{~mm}$ diameter and $80 \mathrm{~mm}$ thick (Figure 1). The disk was firstly treated by a special process to acquire a dual grain structure. Subsequent final heat treatment included a subsolvus solution at $1100^{\circ} \mathrm{C} / 1.5$ hours followed by a $600^{\circ} \mathrm{C}$ salt quench and an aging treatment $\left(860^{\circ} \mathrm{C} / 8\right.$ hours, air cool). The disk was machined and then cut into sections for microstructural features evaluating and mechanical properties testing. 


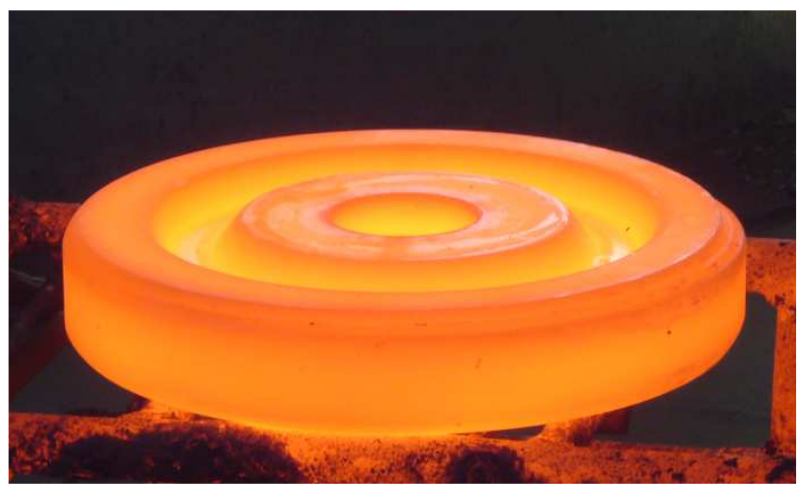

Figure 1. The experimental disk during heat treatment.

\section{Microstructural Characterization}

Grain sizes were determined on a transverse macro-section. Figure 2 shows the locations chosen for grain size assessment and the measuring results (in ASTM). Converting the measuring data to a matrix, a distribution contour plot of the average grain sizes in the transverse section of the disk can be created (Figure 3). The average grain size varies with radial distance in the disk. In the bore region grain size is about $9.5-11 \mu \mathrm{m}$ (ASTM 10.5-10). The grain size increases to about $45-55 \mu \mathrm{m}$ (ASTM 6-5.5) in the rim region. The transition zone is in web region and about $40 \mathrm{~mm}$ in width, grain size varies from $16 \mu \mathrm{m}$ to $45 \mu \mathrm{m}$ (ASTM 9-6). Typical grain microstructures representative of different regions are shown in Figure 4. As shown in Figure 5, $\gamma^{\prime}$ precipitates in different regions of the disk have also different distributions. A bimodal distribution of $\gamma^{\prime}$ precipitates in bore region can be observed. But in web and rim regions, $\gamma^{\prime}$ precipitates appear to be a tri-model distribution.

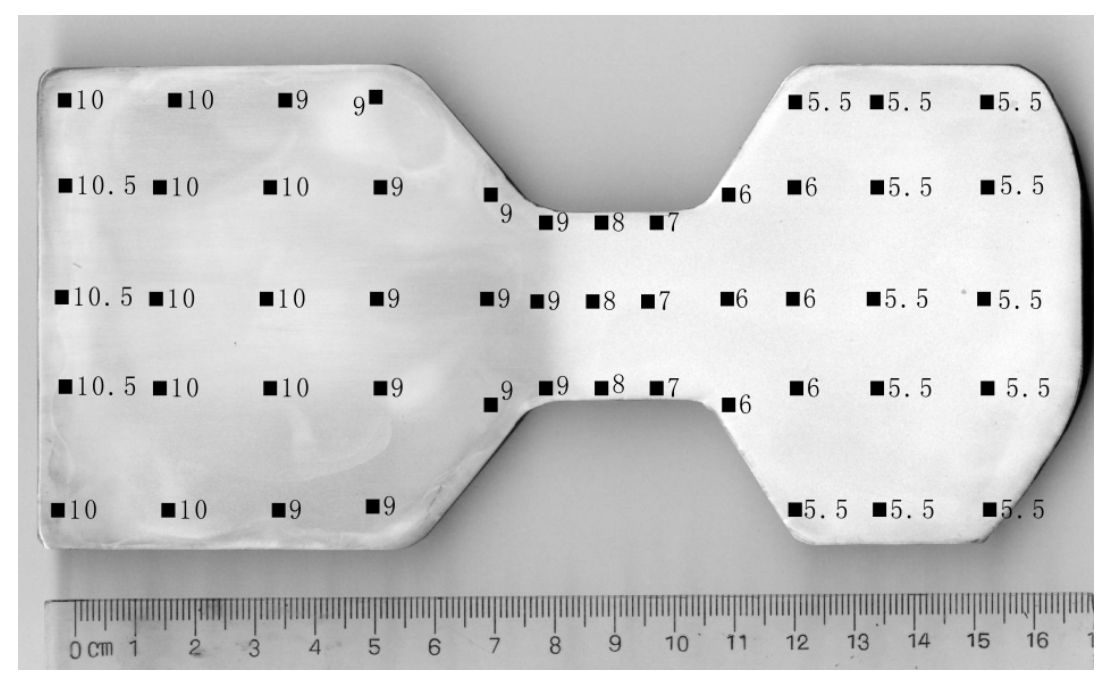

Figure 2. Measuring locations and results of the grain size (in ASTM) assessment on a transverse macro-section of the disk. 


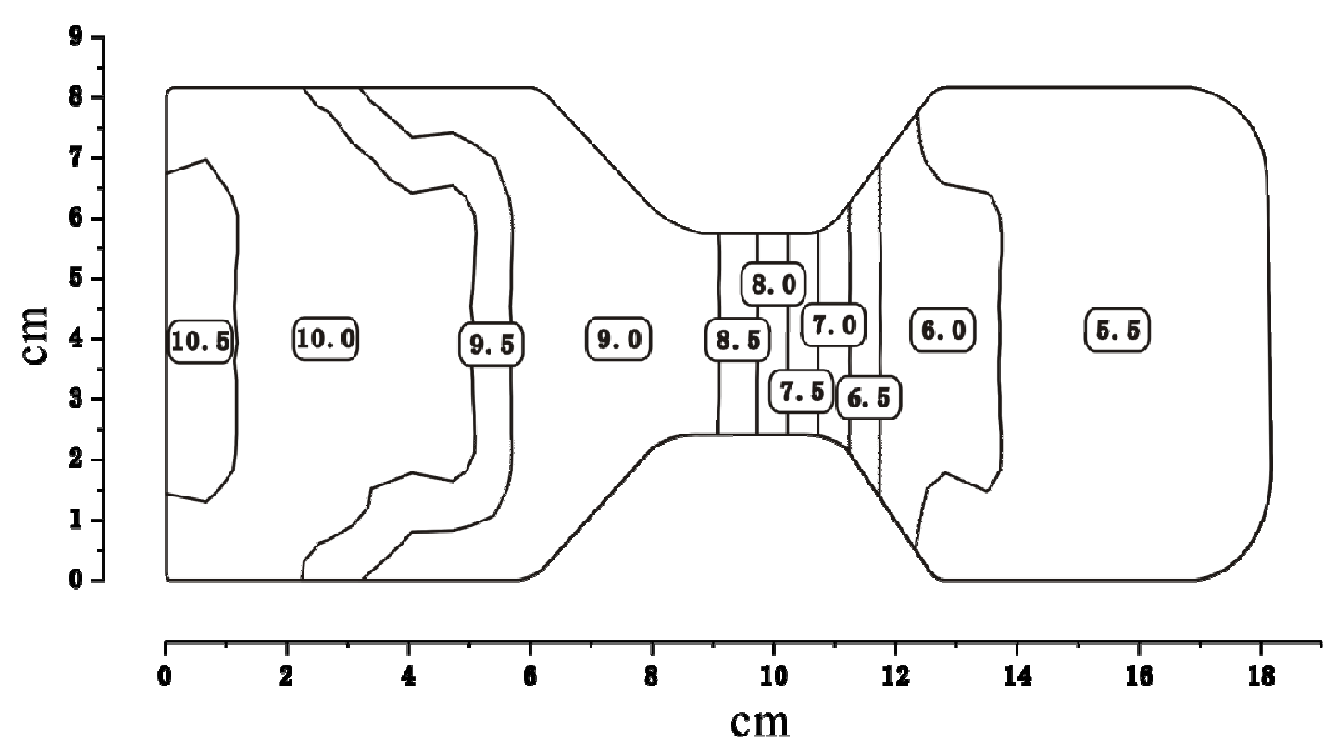

Figure 3. Average grain size (in ASTM) distribution of the disk

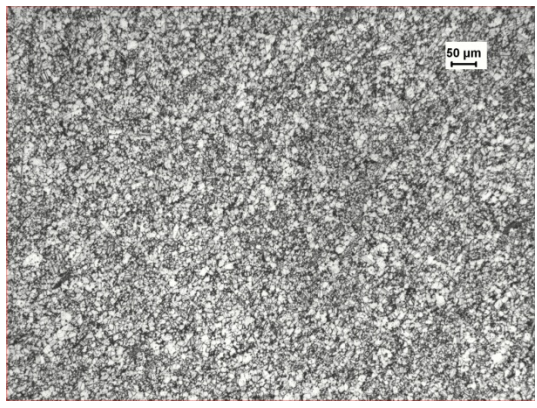

Bore

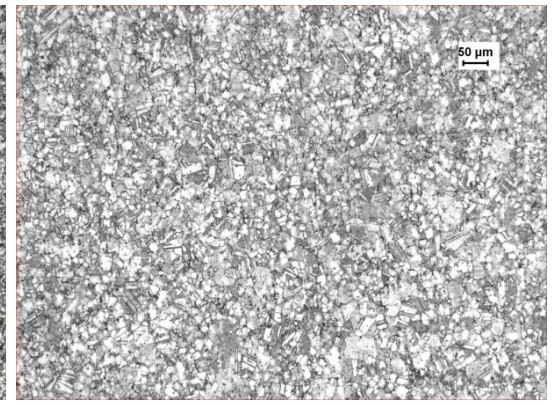

Web

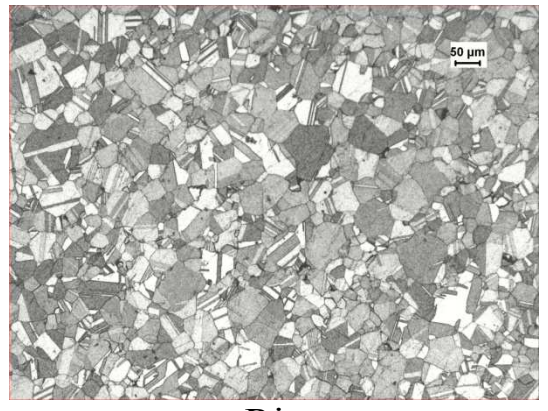

Rim

Figure 4. Typical grain microstructures in bore, web and rim regions of the disk

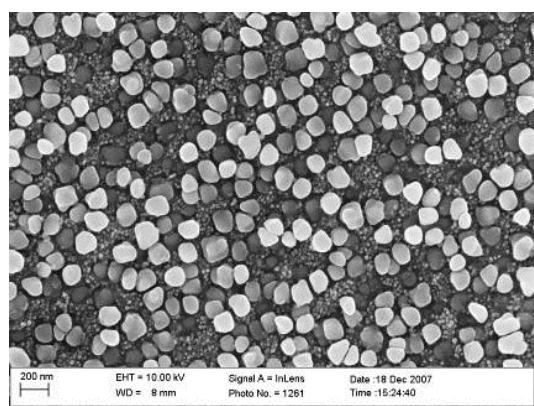

Bore

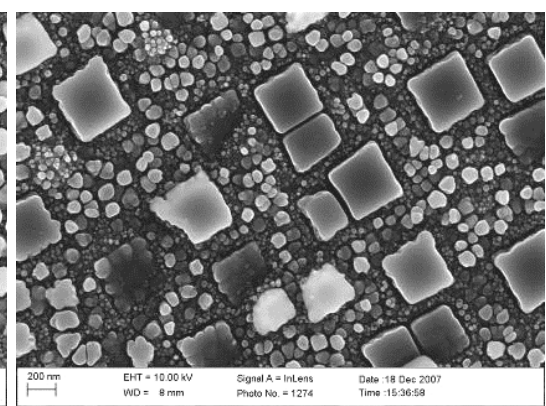

Web

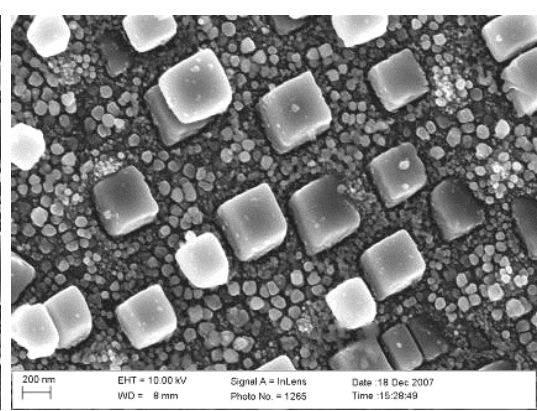

Rim

Figure 5. Morphologies and distributions of $\gamma^{\prime}$ precipitates in bore, web and rim regions of the disk

\section{Mechanical Properties}

Mechanical properties, including tensile, stress rupture, plastic creep, low cycle fatigue, fatigue crack growth rate, fracture toughness, impact and hardness were tested on specimens from different regions of the disk. Tensile tests were conducted at room temperature, $650^{\circ} \mathrm{C}$ and $750^{\circ} \mathrm{C}$ on specimens from each different microstructural region. The results were shown in Table 1. The disk exhibit excellent strength at room and high temperature. The test data reveal obviously a variety correlated with corresponding grain size. Stress rupture properties were determined at $550^{\circ} \mathrm{C} / 1150 \mathrm{MPa}$, $650^{\circ} \mathrm{C} / 1000 \mathrm{MPa}, 750^{\circ} \mathrm{C} / 650 / 690 \mathrm{MPa}$ for bore region and $650^{\circ} \mathrm{C} / 1000 \mathrm{MPa}, 750^{\circ} \mathrm{C} / 650 / 690 \mathrm{MPa}$ for rim region. The results were shown in Table 2 . At $550^{\circ} \mathrm{C}$, the fine grain bore region of the disk has outstanding rupture life on high stress level. But at $650^{\circ} \mathrm{C}$ and $750^{\circ} \mathrm{C}$, the coarse grain rim region offers better stress rupture properties than the fine grain bore region. Creep specimens were examined at $550^{\circ} \mathrm{C} / 1100 \mathrm{MPa} / 100$ hours for bore region and $750^{\circ} \mathrm{C} / 450 \mathrm{MPa} / 100$ hours for rim region. The 
results were shown in Table 3. Both bore and rim regions of the disk display a good creep property. Low cycle fatigue tests were performed at $400^{\circ} \mathrm{C}, 538^{\circ} \mathrm{C}$ on bore specimens and $650^{\circ} \mathrm{C}, 750^{\circ} \mathrm{C}$ on rim specimens using a triangular waveform to a total strain range of 0.85 percent and a strain ratio of $\mathrm{R}_{\varepsilon}=\varepsilon_{\min } / \varepsilon_{\max }=0$, using a frequency of $0.33 \mathrm{~Hz}$. The LCF properties, both in bore and rim, are satisfactory as shown in Table 4 . Fatigue crack growth tests were done at $650^{\circ} \mathrm{C}$ using a maximum load of $4.165 \mathrm{kN}$ and load ratio of 0 . All specimens from bore, web and rim regions had a rectangular gage section $25 \mathrm{~mm}$ wide and $10 \mathrm{~mm}$ thick, with a surface flaw about $0.1 \mathrm{~mm}$ wide and $15 \mathrm{~mm}$ deep produced by electro-discharge machining. Tests were performed with $5 \mathrm{~s}$ and $90 \mathrm{~s}$ dwells at maximum load. The results were illustrated in Figure 6. The resistance to dwell crack growth of the disk increases radially from bore to rim. Fracture toughness tests were conducted at room temperature. Test conditions and results were exhibited in Table 5. The value of provisional fracture toughness $\mathrm{K}_{\mathrm{Q}}$ in rim region is higher than that in bore region. Impact and hardness were measured at room temperature. The results were shown in Table 6 . The values of impact of the disk increase from bore, web to rim. The values of hardness vary inversely.

Table 1. Results of tensile tests

\begin{tabular}{|c|c|c|c|c|c|}
\hline Location & Temp. $\left({ }^{\mathbf{C}} \mathrm{C}\right)$ & U.T.S. $(\mathrm{MPa})$ & $0.2 \%$ Y.S. $(\mathrm{MPa})$ & Elongation (\%) & R.A. (\%) \\
\hline Bore & 22 & 1590 & 1210 & 18.0 & 21.0 \\
\hline Bore & 22 & 1610 & 1210 & 22.5 & 30.5 \\
\hline Web & 26 & 1490 & 1050 & 22.5 & 27.0 \\
\hline Web & 26 & 1570 & 1150 & 21.5 & 29.0 \\
\hline Rim & 26 & 1480 & 1040 & 23.0 & 28.5 \\
\hline Rim & 26 & 1480 & 1030 & 20.0 & 23.0 \\
\hline Bore & 650 & 1500 & 1110 & 13 & 16.5 \\
\hline Bore & 650 & 1460 & 1090 & 17 & 21.0 \\
\hline Web & 650 & 1440 & 1050 & 16.0 & 17.5 \\
\hline Web & 650 & 1480 & 1080 & 17.0 & 18.0 \\
\hline Rim & 650 & 1420 & 985 & 15.0 & 19.0 \\
\hline Rim & 650 & 1420 & 975 & 21.0 & 21.5 \\
\hline Bore & 750 & 1160 & 1040 & 13 & 16.0 \\
\hline Bore & 750 & 1190 & 1050 & 12 & 16.0 \\
\hline Web & 750 & 1140 & 1010 & 13.0 & 15.5 \\
\hline Web & 750 & 1170 & 940 & 15.0 & 17.0 \\
\hline Rim & 750 & 1140 & 915 & 11.0 & 14.5 \\
\hline Rim & 750 & 1170 & 930 & 13.0 & 15.5 \\
\hline
\end{tabular}

Table 2. Results of stress rupture tests

\begin{tabular}{|c|c|c|c|c|}
\hline Location & Temp. $\left({ }^{\circ} \mathrm{C}\right)$ & Stress (MPa) & Rupture life (hours) & Elongation (\%) \\
\hline Bore & 550 & 1150 & $418: 25$ & 5 \\
\hline Bore & 650 & 1000 & $42: 41$ & 8 \\
\hline Rim & 650 & 1000 & $71: 47$ & 3 \\
\hline Bore & 750 & 690 & $12: 25$ & 13 \\
\hline Rim & 750 & 690 & $32: 53$ & 12 \\
\hline Bore & 750 & 650 & $18: 12$ & 14 \\
\hline Rim & 750 & 650 & $69: 55$ & 14 \\
\hline
\end{tabular}

Table 3. Results of creep tests

\begin{tabular}{|c|c|c|c|c|}
\hline Location & Temp. $\left({ }^{\mathrm{o}} \mathrm{C}\right)$ & Stress $(\mathrm{MPa})$ & Time (hours) & Creep Elongation $\%$ \\
\hline Bore & 550 & 1100 & 100 & 0.088 \\
\hline Rim & 750 & 450 & 100 & 0.062 \\
\hline
\end{tabular}


Table 4. Results of low cycle fatigue tests

\begin{tabular}{|c|c|c|}
\hline Location & Temp. $\left({ }^{\circ} \mathrm{C}\right)$ & Fatigue life (cycles) \\
\hline Bore & 400 & 15463 \\
\hline Bore & 538 & 15265 \\
\hline Rim & 650 & 6750 \\
\hline Rim & 750 & 4949 \\
\hline
\end{tabular}
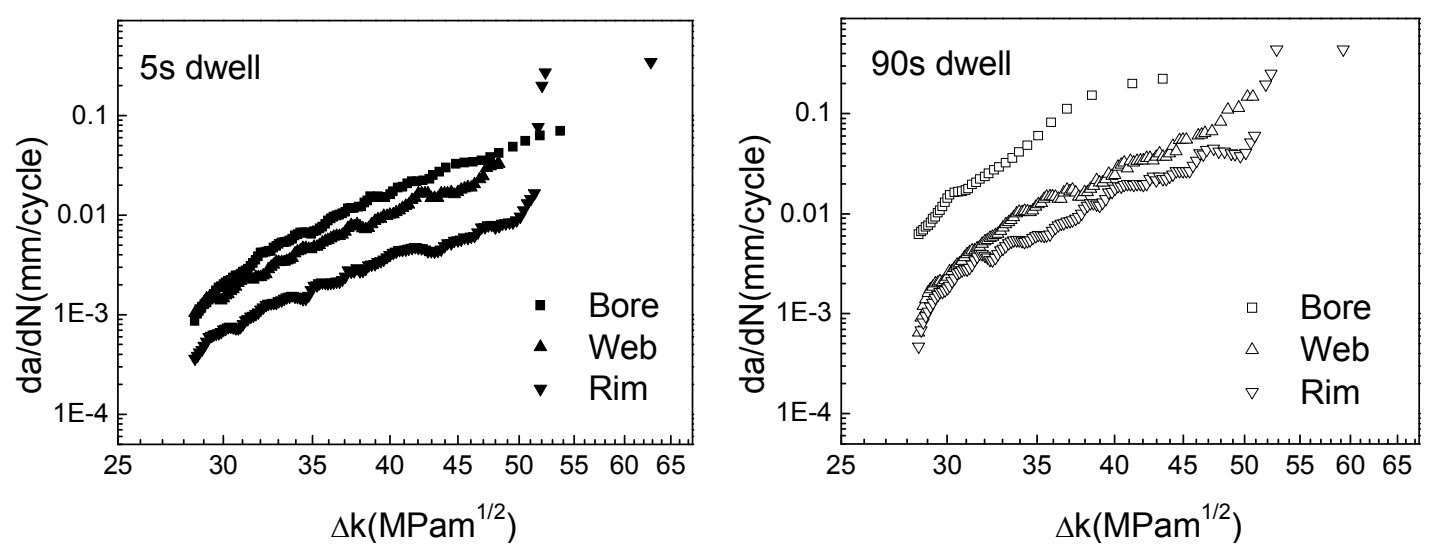

Figure 6. Dwell crack growth rates of the disk

Table 5. Conditions and results of fracture toughness tests

\begin{tabular}{|c|c|c|c|c|c|c|c|}
\hline Location & $\begin{array}{c}\text { Specimen } \\
\text { thickness } \\
\mathrm{B}(\mathrm{mm})\end{array}$ & $\begin{array}{c}\text { Specimen } \\
\text { width } \\
\mathrm{W}(\mathrm{mm})\end{array}$ & $\begin{array}{c}\text { Crack } \\
\text { length } \\
\mathrm{a}(\mathrm{mm})\end{array}$ & $\begin{array}{c}\text { Condition } \\
\text { Load } \\
\mathrm{P}_{\mathrm{q}}(\mathrm{kN})\end{array}$ & $\begin{array}{c}\text { Maximum } \\
\text { load } \\
\mathrm{P}_{\max }(\mathrm{kN})\end{array}$ & $\begin{array}{c}\mathrm{K}_{\mathrm{Q}} \\
\left(\mathrm{MPam}^{1 / 2}\right)\end{array}$ & Valid \\
\hline Bore & 25.08 & 50.02 & 26.71 & 83.125 & 108.438 & 158 & No \\
\hline Rim & 25.14 & 50.17 & 26.97 & 89.375 & 104.688 & 172 & No \\
\hline
\end{tabular}

Table 6. Results of impact and hardness tests

\begin{tabular}{|c|c|c|}
\hline Location & Impact, $\mathrm{A}_{\mathrm{KU} 2}(\mathrm{~J})$ & Hardness $(\mathrm{HB})$ \\
\hline Bore & 37 & 440 \\
\hline Web & 50 & 411 \\
\hline Rim & 51 & 409 \\
\hline
\end{tabular}

\section{Summary}

A FGH96 superalloy disk with a dual microstructure was sectioned for microstructural features evaluating and mechanical properties testing. The disk has a fine grain structure (ASTM 10-10.5) in the bore region and a coarse grain structure (ASTM 5.5-6) in the rim region. The grain size transition zone locates in the web region of the disk and is about $40 \mathrm{~mm}$ in width. The $\gamma^{\prime}$ precipitates in the disk appear to be a bimodal distribution for the bore region and a tri-model distribution for the web and rim regions. Mechanical testing displayed the fine grain bore region has a high tensile and rupture strength, exceptional LCF life and creep resistance at lower temperature. At higher temperature, the coarse grain rim region displays better properties in stress rupture, creep, fatigue crack growth, fracture toughness and impact than that of bore region. The properties of the grain transition web region are intervenient between bore and rim regions. 


\section{References}

[1] K. M. Chang "Method of Making High Strength Superalloy Components with Graded Properties”, US Patent 4,820,358, April 11, 1989

[2] G. F. Mathey "Method of Making Superalloy Turbine Disks Having Graded Coarse and Fine Grains”, US Patent 5,312,497, May 17, 1994

[3] S. Ganesh and R. G. Tolbert "Differentially Heat Treated Article, and Apparatus and Process for the Manufacture thereof", US Patent 5,527,020, June 18, 1996

[4] J. Gayda and D. Furrer "Dual-Microstructure Heat Treatment", Advanced Materials \& Processes, July 2003, 36-39

[5] M. G. Yan et al., eds., China Aeronautical Materials Handbook, vol. 5 (Beijing: Standards Press of China, 2001), 44-47

[6] Y. Zhang, Y. W. Zhang, Y. Tao et al. "Microstructural Evolution of FGH96 Powder Superalloy", Journal of Materials Engineering, Supplement 2002, 62-64

[7] Y. Tao, J. T. Liu, Y. W. Zhang et al. "Effects of Grain Size on Properties of FGH4096 Alloy", High Temperature Structure Materials in Power and Energy Industry, ed. Z. Y. Zhong et al. (Beijing: Metallurgical Industry Press, 2007), 524-527 